\title{
1 Neophobia and innovation in critically endangered Bali myna, Leucopsar rothschildi
}

2

3 Rachael Miller ${ }^{1} *$, Elias Garcia-Pelegrin ${ }^{+1}$, Emily Danby ${ }^{1}$

4

$5{ }^{1}$ Department of Psychology, University of Cambridge, Cambridge, UK

6

$7 \quad *$ Rachael Miller: Joint first, senior and corresponding author. Email: rmam3@cam.ac.uk

$8+$ Elias Garcia-Pelegrin: Joint first author

9

10

11

12 Short title: Neophobia and innovation in Bali myna 


\section{Abstract}

15 Cognition underlies animal behaviour, which is key to successful conservation strategies, yet

16 largely under-utilised in conservation, though there are recent calls for closer integration.

17 Conservation-relevant cognitive abilities can impact on adaptability and survival, such as

18 neophobia, e.g., responses to novelty, and innovation e.g., problem-solving, particularly in

19 today's changing world. Bali myna are a critically endangered endemic species, which are a

20 focus of active conservation efforts, including reintroductions. Therefore, gathering cognitive

21 data can aid in improving and developing conservation strategies, like pre-release training

22 and individual selection for release. In 22 captive Bali myna, we tested neophobia (novel

23 object, novel food, control conditions), innovation (bark, cup, lid conditions) and individual

24 repeatability. We found effects of condition and social environment, including longer

25 latencies to touch familiar food in presence than absence of novel items, and between

26 problem-solving tasks, as well as in the presence of conspecifics, compared with being alone,

27 or with conspecifics and competing heterospecifics. Individuals were repeatable in latency

28 responses: 1) temporally in both experiments; 2) contextually in innovation experiment and

29 between both experiments (and approach order), suggesting a stable behaviour trait. These

30 findings are an important starting point for improving conservation strategies in Bali myna

31 and other similarly threatened species.

33 Keywords: neophobia, problem-solving, innovation, Bali myna, conservation 


\section{Background}

36 Cognitive abilities such as perception, learning, decision making and memory [1], have been

37 long accepted as playing a vital role in animal behaviour in the wild. Crucially, they

38 determine in part an animal's ability to adapt (i.e., respond flexibly) to variation in ecology

39 and the social environment [2,3], and individual differences have important fitness and

40 survival implications [4]. Indeed, cognition correlates with fitness measures [5]. As human

41 actions increasingly impact on the environment, animals are often required to adapt quickly

42 to evolutionary novel cues, with new selection pressures placed on cognitive adaptations [6].

43 Despite this, cognitive research has been largely under-utilised in conservation strategies

$44 \quad[3,6-8]$. Understanding how animals perceive and learn about danger and reward can aid

45 conservation, particularly those conservation strategies that rely on manipulating behavioural

46 responses [3, 6]. For example, the way that birds perceive human-made structures, like

47 turbines, has influenced the development of wind farm deterrents [6]. Further, it is not yet

48 known how individual cognitive phenotypes impact survival post-release and establishing

49 this can allow more effective selection of suitable individuals for release.

50 Reintroduction programmes are a vital conservation tool, but they often fail as released 51 animals cannot forage effectively, recognise predators and/or breed successfully. In animal

52 reintroductions or translocations, the risk of mortality to predation in previously captive

53 animals with little predator experience is high, therefore antipredator training is beginning to

54 be included in pre-release preparations [9]. Antipredator training may be more successful in

55 species that have effective responses to similar predators. For example, New Zealand robins

56 exposed to unfamiliar predators (stoats) have learned to recognise them, impacting on their

57 survival [10]. Recently, there has been a call for closer integration of cognition and

58 conservation research $[3,6,8]$. This type of research is timely and critical given the rapidly

59 declining animal populations worldwide.

60 Examples of conservation-relevant cognitive abilities include innovation and neophobia.

61 Innovation can be defined as solving a novel problem or finding a different solution to a

62 familiar problem, which influences how animals adjust to new or changing environments [11,

63 12] (behaviour resulting from a combination of cognitive and non-cognitive processes). For

64 example, innovative common myna (Acridotheres tristis) are slower than non-innovative

65 myna to change their behaviour in response to a changing environment [13]. Neophobia -

66 e.g., aversion to novelty - is linked with life-history variation and has fitness implications [4].

67 Neophobia can aid in avoidance of unfamiliar dangers, though can also prevent adaptation to 
68

69

70

71

new environments or foods [14]. How an animal responds to novelty can predict post-release outcomes [15].

An understanding of how species and individuals respond to novelty and approach new problems is vital both for cognitive research and applied conservation, particularly as the world is increasingly urbanised, and many species need to adapt to human-generated environmental changes and the inevitable associated novelty [6]. Individuals or species with higher innovation and lower neophobia may be more adaptable in regard to coping with changing habitat/degradation, though these traits may increase chances of being trapped by humans. Differentiating between responses to these two threats is important as populations/areas face different levels of risk. For example, individual common myna that inhabit urban environments show lower neophobia and utilise novel food resources more quickly compared with those living in rural areas [16].

Furthermore, individuals may show behaviours that are temporally and contextually repeatable, or alternatively, show inconsistency in their responses [17]. This may be influenced by various factors, such as species, task or measures tested, seasonality as well as developmental and social influences $[6,18]$. Individual performance may also correlate across tasks. For instance, in feral pigeons (Columba livia) and zenaida doves (Zenaida aurita), latency to learn a foraging task covaried with individual neophobia level [19].

Bali myna are a critically endangered species that are endemic to Bali. We selected this species because: (1) they are highly threatened ( $<50$ adults in the wild; Birdlife.org); (2) face threats like illegal trapping/ poaching for the pet trade and habitat degradation [20] that could be mitigated through behavioural research and training which must be informed by cognitive research; (3) there is active conservation action with varying success across different sites (need to continually release birds to try to boost small populations and open questions regarding ways to boost survival, such as predator/trapping avoidance and use of novel habitats and safe, novel foods), including reintroduction, which enables pre- and post-release research; (4) there is currently minimal published cognitive/behavioural data on Bali myna though there is a reasonably sized zoo population ( $~ 950$ individuals across $\sim 170$ institutions worldwide, with 90 individuals in UK zoos; ZIMS, 2021 - zims.species360.org, accessed September 2021).

We aimed to quantify individual and species-level performance in innovation and neophobia tasks in captive Bali myna, using comparable paradigms as in some previous species [13, 14, 21]. We tested (1) innovation through 3 simple problem-solving tasks (flip bark, flip cup and lift lid to obtain preferred insect; 3x 20-minute trials per task) and (2) 
102 neophobia through presentation of 3 types of novel objects and novel foods (jelly) placed

103 beside familiar food, compared with familiar food alone (i.e., control; run 3x 20-minute trials

104 per condition for individual repeatability) [17]. Further, we tested whether individual

105 performance correlated across the two experiments, i.e., whether less neophobic individuals

106 were also quicker to approach the problem-solving task(s). We tested individuals within three

107 UK zoos, primarily in social settings as it was not possible to separate individuals for testing.

108 We expected that, similar to other species (e.g., ravens (Corvus corax) [22]), social context

109 would influence neophobia and innovation in Bali myna. As the birds were particularly

110 important for the captive breeding programme, and it was necessary for testing to overlap

111 with breeding season due to funding availability, these experimental designs were specifically

112 selected to minimise researcher presence or disturbance in aviaries (e.g., no training

113 requirements).

114 As there has been little previous published cognitive research with Bali myna, we were

115 reliant primarily on anecdotal/filmed reports before testing. For example, filmed reports of

116 wild-bred juveniles learning to flip cow dung for insects, although their great, great

117 grandparents did not do this in the aviary before release, yet they have worked it out (Donato,

118 2020, personal communication). These reports indicate innovation may be present in this

119 species, though this has not previously, to our knowledge, been tested. Anecdotal zoo-keeper

120 reports (e.g. Miller, 2021, personal communication) suggested that these birds are relatively

121 neophobic, certainly compared to other similar myna species, like common myna - which are

122 a successful invasive species in Australia and other countries [13]. We expected neophobia to

123 vary across individuals and between conditions, e.g., novel food versus novel object

124 compared with control, as indicated in other species [21, 23]. Finally, we expected that

125 individual performance would correlate across tasks, as in other species (pigeons [24];

126 corvids [25]; birds and primates [26]). This study provides the first assessment of two key

127 cognitive aspects that influence adaptability in captive Bali myna as a necessary starting point

128 for testing cognition in order to implement findings in active conservation in Bali.

Methods

131

We pre-registered this study prior to data collection at OSF: shorturl.at/ftMV1. 
136 Subjects were 22 captive Bali myna (10 males; 10 females; 2 unknown sex) housed across 10

137 aviaries within three UK zoological collections (Table 1). They were identifiable using

138 coloured or metal leg rings. Subjects were primarily adults (>1 year old, D.O.B. range: 2011-

139 2020), other than two juveniles that were successfully reared by one pair in July 2021. Each

140 zoo housed their birds according to their standard ethical and housing conditions, with a

141 range of aviary sizes, though all (except 1 temporary inside aviary) being primarily outside,

142 with a wide array of perching, planting and substrates available. As it was not possible to

143 individually separate birds at any zoo due to ethical and housing constraints, as well as time

144 restrictions, we tested the birds according to their current housing situation, which included

145 the presence of conspecifics (19/22 subjects) and other bird species (13/22 subjects; Table 1).

146 The other bird species were divided into non-competitors and competitors, based on whether

147 or not they routinely visited the test sites, ate Bali myna food and/or interacted with

148 experimental stimuli/apparatuses (Table 1). Participating in testing was voluntary for the

149 birds - all available birds were present in every trial, other than the two juveniles who were

150 only present for round 2 and 3 (as hatched after round 1 complete). Data collection took place

151 from May-July 2021, which includes the breeding season for this species (timing selected due

152 to funding availability for this limited period). Nest boxes were present in the aviaries that

153 housed male/female pairs for periods of testing, and one pair did successfully reproduce two

154 chicks.

155

156 Table 1. Subject information

\begin{tabular}{|l|l|l|l|l|l|l|}
\hline UK Zoo & Aviary & $\begin{array}{l}\text { Sex } \\
\text { (male, } \\
\text { female, } \\
\text { unsexed) }\end{array}$ & $\begin{array}{l}\text { Age } \\
\text { (adult, } \\
\text { juvenile) }\end{array}$ & $\begin{array}{l}\text { Mixed exhibit } \\
\text { species inc. } \\
\text { whether } \\
\text { “competitor" or } \\
\text { “non-competitor" }\end{array}$ & $\begin{array}{l}\text { Testing } \\
\text { site } \\
\text { within } \\
\text { aviary }\end{array}$ & Notes \\
\hline $\begin{array}{l}\text { Birdworld, } \\
\text { Farnham }\end{array}$ & $\begin{array}{l}\text { Group } \\
(\mathrm{n}=7)\end{array}$ & 3.4 & Adult & $\begin{array}{l}\text { Competitor: } 1 \\
\text { Lilac-breasted } \\
\text { roller, Coracias } \\
\text { caudatus, 3 wonga } \\
\text { pigeon, } \\
\text { Leucosarcia } \\
\text { melanoleuca, } 2\end{array}$ & $\begin{array}{l}\text { Main } \\
\text { aviary }\end{array}$ & $\begin{array}{l}\text { 1 hatched } \\
2018 ; \\
\text { others } \\
2020\end{array}$ \\
\hline
\end{tabular}




\begin{tabular}{|c|c|c|c|c|c|c|}
\hline & & & & $\begin{array}{l}\text { white-browed } \\
\text { robin-chat, } \\
\text { Cossypha heuglini }\end{array}$ & & \\
\hline $\begin{array}{l}\text { Birdworld, } \\
\text { Farnham }\end{array}$ & Pair 1 & 1.1 & Adult & $\begin{array}{l}\text { Non-competitor: } 2 \\
\text { Edward pheasant, } \\
\text { Lophura edwardsi }\end{array}$ & $\begin{array}{l}\text { Inside } \\
\text { area }\end{array}$ & $\begin{array}{l}\text { Reared } 2 \\
\text { chicks in } \\
\text { July } 2021 \\
\text { - present } \\
\text { in aviary } \\
\text { during } \\
\text { round } 2 \text { of } \\
\text { testing }\end{array}$ \\
\hline $\begin{array}{l}\text { Birdworld, } \\
\text { Farnham }\end{array}$ & Pair 2 & 1.1 & Adult & None & $\begin{array}{l}\text { Covered } \\
\text { area of } \\
\text { main } \\
\text { aviary }\end{array}$ & \\
\hline $\begin{array}{l}\text { Birdworld, } \\
\text { Farnham }\end{array}$ & $\begin{array}{l}\text { Juveniles } \\
(\mathrm{n}=2)\end{array}$ & 0.0 .2 & Juvenile & None & $\begin{array}{l}\text { Main } \\
\text { aviary }\end{array}$ & $\begin{array}{l}\text { Tested } \\
\text { with } \\
\text { parents for } \\
\text { round } 2 \text {, } \\
\text { then alone } \\
\text { for round } \\
3\end{array}$ \\
\hline $\begin{array}{l}\text { Cotswolds } \\
\text { Wildlife } \\
\text { Park \& } \\
\text { Gardens }\end{array}$ & Pair 1 & 1.1 & Adult & $\begin{array}{l}\text { Competitor: } 2 \\
\text { white-spotted } \\
\text { laughing thrush, } \\
\text { Lanthocincla bieti, } \\
6 \text { azure-winged } \\
\text { magpie, Cyanopica } \\
\text { cyanus, } 2 \text { pink } \\
\text { pigeon, Nesoenas } \\
\text { mayeri, } 2 \\
\text { Madagascar } \\
\text { partridge, }\end{array}$ & $\begin{array}{l}\text { Main } \\
\text { aviary }\end{array}$ & \\
\hline
\end{tabular}




\begin{tabular}{|c|c|c|c|c|c|c|}
\hline & & & & $\begin{array}{l}\text { Margaroperdix } \\
\text { madagarensis }\end{array}$ & & \\
\hline $\begin{array}{l}\text { Cotswolds } \\
\text { Wildlife } \\
\text { Park \& } \\
\text { Gardens }\end{array}$ & Pair 2 & 2.0 & Adult & $\begin{array}{l}\text { None in first aviary } \\
\text { (round } 1 \& 2 \text { ); non- } \\
\text { competitor: } 1 \text { pink } \\
\text { pigeon and two } \\
\text { Palawan peacock } \\
\text { pheasant, } \\
\text { Polyplectron } \\
\text { napoleonis, in } \\
\text { second aviary } \\
\text { (round 3) }\end{array}$ & $\begin{array}{l}\text { Main } \\
\text { aviary }\end{array}$ & $\begin{array}{l}\text { Moved } \\
\text { enclosure } \\
\text { July } 2021\end{array}$ \\
\hline $\begin{array}{l}\text { Waddesdon } \\
\text { Manor }\end{array}$ & Pair 1 & 1.1 & Adult & $\begin{array}{l}\text { Non-competitor: } 1 \\
\text { Rothchild's } \\
\text { peacock pheasant, } \\
\text { Polyplectron } \\
\text { inopinatum }\end{array}$ & $\begin{array}{l}\text { Main } \\
\text { aviary }\end{array}$ & \\
\hline $\begin{array}{l}\text { Waddesdon } \\
\text { Manor }\end{array}$ & Single 1 & 1.0 & Adult & None & $\begin{array}{l}\text { Main } \\
\text { aviary }\end{array}$ & $\begin{array}{l}\text { Temporary } \\
\text { single } \\
\text { housing } \\
\text { (new } \\
\text { arrival) }\end{array}$ \\
\hline $\begin{array}{l}\text { Waddesdon } \\
\text { Manor }\end{array}$ & Single 2 & 0.1 & Adult & None & $\begin{array}{l}\text { Main } \\
\text { aviary }\end{array}$ & $\begin{array}{l}\text { Temporary } \\
\text { single } \\
\text { housing } \\
\text { (awaiting } \\
\text { pairing } \\
\text { with new } \\
\text { arrival) }\end{array}$ \\
\hline $\begin{array}{l}\text { Waddesdon } \\
\text { Manor }\end{array}$ & Single 3 & 0.1 & Adult & None & $\begin{array}{l}\text { Inside } \\
\text { house }\end{array}$ & $\begin{array}{l}\text { Temporary } \\
\text { single } \\
\text { housing } \\
\text { (awaiting }\end{array}$ \\
\hline
\end{tabular}


157

158

159

160

161

162

163

164

165

166

167

168

169

170

171

172

173

174

175

176

177

178

179

180

181

182

183

\begin{tabular}{|l|l|l|l|l|l|}
\hline & & & & & $\begin{array}{l}\text { pairing or } \\
\text { relocation })\end{array}$ \\
\hline
\end{tabular}

\section{Pilot}

Prior to testing, we visited each zoo at least twice to set up test sites (primarily situated where the birds were usually fed), positions for video cameras (min 1 metre, preferably further where possible, from test sites in case birds responded to the camera presence) and recorded latencies to approach familiar food (i.e., regular diet) when fed in the morning (no experimental manipulation).

\section{Neophobia experiment}

\section{Apparatus/materials}

We included three conditions: control (regular diet); novel food $\left(3 \mathrm{~cm}^{3}\right.$ blocks of coloured jelly - orange, purple and green); and novel object (human-made items; Figure 1) - each novel item was presented alongside the regular diet (i.e., familiar food). The regular diet was presented in the same food bowl that it would usually be served in at each aviary. Insects (mealworms, waxworms or morio worms) were added to the food bowl. The novel item was typically presented in a familiar food bowl (new bowl present in aviary for several weeks prior to testing). The novel items were selected as such to be comparable with research in corvids $[21,23]$ so the data may be useful for comparative research [27].
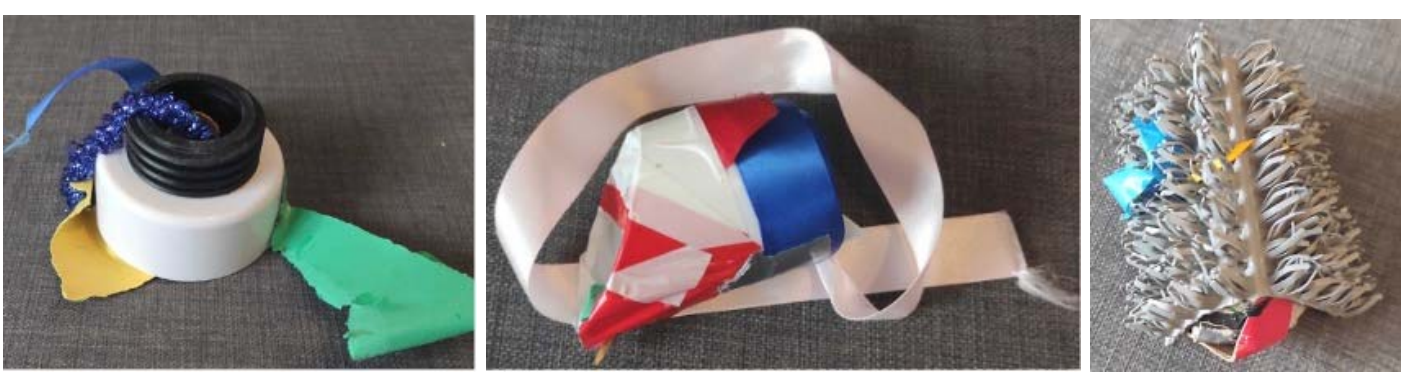

Figure 1. Novel objects

\section{Procedure}


184 We measured behavioural responses to novel items presented alongside familiar food

185 compared with familiar food alone. On novel item condition trials, the novel item was placed

$186 \sim 20 \mathrm{~cm}$ from the familiar food bowl, in the same location for each trial so consistent within

187 individual and aviary. For video coding, the trial commenced once the experimenter had left

188 the immediate testing area (i.e., out of camera shot). Each trial lasted 20 minutes in total -

189 determined during piloting to be sufficient time for the majority of individuals to reliably

190 approach the familiar food. Where there was more than one Bali myna subject in an aviary,

191 we established more than one test site using feed sites that already existed or else following at

192 least 2 weeks habituation (i.e., pair-housed aviaries received one or two test sites depending

193 on availability for test sites, the group-housed aviary received three test sites). The

194 experimenter was not present in the aviary during testing.

195 We ran three tests 'rounds' in total - within each round were three trials, one per

196 condition ( 9 trials total), over 3 days, with approx. 2 weeks between rounds, therefore lasting

197 approx. 6 weeks per zoo. Testing occurred in the morning alongside the daily presentation of

198 their regular diet - therefore the birds were not fed prior to testing, though were not deprived

199 and had access to any leftover food from the previous day as well as any natural foraging

200 opportunities available like wild insects (as all included outside aviary spaces). The control

201 trial (familiar food only) was run on day 2, with the novel food or novel object

202 counterbalanced between day 1 or 3 across aviaries and rounds, so that the control took place

203 within 24 hours of each test condition. The main variable of interest was latency to touch

204 familiar food, indicating the time taken for an individual to touch a familiar food when a

205 novel item was present, with avoidance being interpreted as neophobia (as per [14, 21, 23]).

207 Innovation Experiment

209 Apparatus/materials

211 We included three problem-solving tasks (Figure 2), with a preferred insect as a reward,

212 primarily waxworms or morio worms. Insects were humanely killed by removing their head

213 before testing to prevent them moving away. 

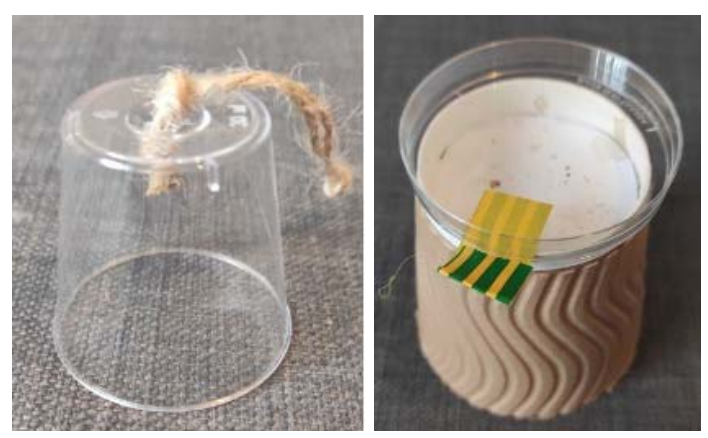

216 Figure 2. Problem-solving tasks 1 and 2. 1) cup can be lifted to access worm e.g., by pulling

217 string or pushing cup over; 2) lid can be removed e.g., by pushing lid or lifting tab. Problem-

218 solving task 3 was a piece of wood bark that could be pushed or lifted to access worm.

\section{Procedure}

Each problem-solving task was baited with a preferred reward and required the subject to move an object (lid, cup, bark) to access the reward. In task 1 and 2 (lid and cup), the reward was visible, whilst in task 3 (bark), it was only partially visible (worm placed under bark so the tip of the body was still visible). We selected these tasks as they were relatively simple given that all subjects were unhabituated and unfamiliar with cognitive testing participation, had more than 1 possible method of 'solving' and were comparable to previous research with common myna [13]. Each task was presented 3x over 3 days, for 20-minute trials per aviary, over the course of a 6 week period (testing every 2 weeks). Testing occurred in the morning after the neophobia testing was complete. We presented one set of each task per subject for the single- and pair-housed subjects, and four sets for the group-housed subjects. As with neophobia, the experimenter was not present in the aviary during testing, and the video was coded from when the experimenter left the test area(s). If the subject solved the task within the first 5 minutes, the experimenter re-baited it with a new reward item. We measured several variables but namely: latency to touch, and frequency of peck and solve, as well as whether the subject solved the task once or twice per trial.

\section{Data Analyses}

240 We recorded all trials and coded all videos using Solomon Coder [28] - the primary coder

241 (E.D.) was unfamiliar with the species and hypotheses prior to coding. We second coded 12\% of videos and inter-rater reliability was high: Cohen's Kappa $=0.8$. 
243 For the neophobia experiment, we were interested in two main questions: 1. Testing

244 effects of condition, round and social environment 2. Individual repeatability over round and

245 condition, with the main dependent variable being latency to touch familiar food (0-1200

246 seconds). Analysis was run using R (version 4.1.0). For Q1, we conducted a Generalised

247 Linear Mixed Model (GLMM) to test whether the main effects of condition (control, novel

248 food, novel object), round (1-3) and social environment (1. alone, 2. conspecific present

249 and/or non-competing heterospecifics i.e., that do not touch Bali myna food, 3. conspecific

250 present and competing heterospecific i.e., that do touch their food) influenced latency to

251 touch familiar food, with individual as a random effect, using likelihood ratio tests (drop1()

252 function) and Tukey comparisons for post-hoc comparisons (package multcomp, function

253 glht()). We checked whether nesting individual within aviary as a random effect, and

254 separately, whether including sex as a main effect improved the model, but did, so we

255 proceeded with individual as a random effect and without sex as a main effect for a more

256 parsimonious model. For Q2, we tested individual repeatability over time (i.e., across rounds)

257 and over condition using intraclass correlation coefficients (ICCs) (per [23]) in SPSS (version

258 27).

259 For the innovation experiment, we checked whether frequency to peck correlated with

260 frequency to solve using two-tailed Spearman's correlations on trials without zeros $(73 / 198$

261 trials) in SPSS. Although $77 \%$ of subjects interacted with the tasks at least once, the data

262 were heavily skewed towards zero. We therefore found that GLMM's were not the most

263 suitable approach, so used non-parametric statistics in SPSS for this analysis - namely,

264 Wilcoxon signed ranks tests and Mann-Whitney U-tests, with Bonferroni corrections applied

265 for multiple comparisons. We compared condition (bark, cup, lid), trial (1-3) and social

266 environment on two variables of interest: 1) latency to approach task, and 2) frequency of

267 peck (which correlated with frequency to solve). We selected these two variables as they

268 showed the highest variability across subjects.

269 Finally, we tested whether individual performance correlated across the two experiments

270 using intra-class correlation coefficient (ICCs). As subjects were temporally repeatable in

271 both experiments, we created mean scores across round (neophobia) and trial (innovation).

272 We then correlated individual latency to touch familiar food in the object condition of the

273 neophobia experiment with latency to approach in the problem-solving tasks using these

274 mean scores. Furthermore, we used the mean scores to check whether order of approach

275 correlated across the problem-solving tasks and the neophobia tasks within each aviary using

276 ICCs. 
278 Example video trials can be found at: https://youtu.be/EngP6mThj4M

279

280

\section{Results}

281

\section{Neophobia Experiment: Testing Effects of Condition, Round and Social Environment}

Latency to touch familiar food differed between conditions (GLMM: $X^{2}=62.389$, df $=2, \mathrm{p}<$

$0.001)$ and social environment $\left(X^{2}=8.786, \mathrm{df}=2, \mathrm{p}=0.012\right)$, but not between test rounds $\left(X^{2}\right.$ $=3.436, \mathrm{df}=2, \mathrm{p}=0.179)$. The birds waited longer with a novel object or novel food present compared to the control condition (Tukey contrasts: novel object - control, $\mathrm{z}=6.902, \mathrm{p}<$ 0.001; novel food - control, $\mathrm{z}=3.665, \mathrm{p}<0.001)$, and they waited longer when a novel object was present than when a novel food was present $(\mathrm{z}=5.015, \mathrm{p}<0.001)$ (Figure 3A). They waited longer when conspecifics and non-competing heterospecifics present (2) compared with when conspecifics and competing heterospecifics present (3; Tukey contrasts: $\mathrm{z}=-2.961, \mathrm{p}=0.008$ ). There was no difference in latencies when alone (1) compared to conspecific and/or non-competing heterospecifics $(2 ; \mathrm{z}=1.106, \mathrm{p}=0.505)$, or alone (1) compared to conspecific and competing heterospecifics present $(3 ; \mathrm{z}=-0.952, \mathrm{p}=0.603$;
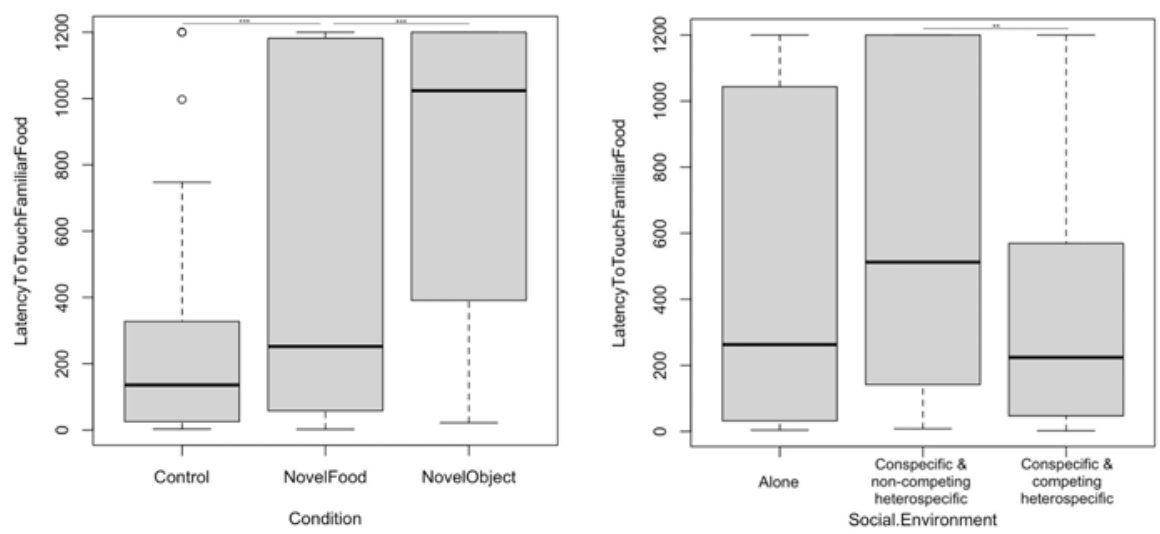

Figure 3. Latency to touch familiar food (seconds) differed by A) condition and B) social environment. Raw data; lines represent median. $* * * \mathrm{p}<0.001 ; * * \mathrm{p}<0.01$ 
303 In the neophobia experiment, we found that individuals were temporally repeatable across 3

304 test rounds (intra-class correlation coefficient: $\mathrm{N}=22, \mathrm{ICC}=0.632, \mathrm{p}<0.001, \mathrm{CI}=0.435$ -

305 0.768). Individuals were not contextually repeatable across novel item conditions (novel

306 object, novel food) in their responses to novelty (ICC: $\mathrm{N}=22, \mathrm{ICC}=0.278, \mathrm{p}=0.103, \mathrm{CI}=$ -

307 0.199-0.565). Within condition, they were temporally repeatable within the control condition,

308 but not within the two novel item conditions (control: $\mathrm{N}=22, \mathrm{ICC}=0.0 .543, \mathrm{p}<0.02, \mathrm{CI}=$

309 0.038-0.805; novel object: $\mathrm{N}=22, \mathrm{ICC}=0.287, \mathrm{p}=0.182, \mathrm{CI}=-0.501-0.696$; novel food: $\mathrm{N}$

$310=22, \mathrm{ICC}=0.278, \mathrm{p}=0.183, \mathrm{CI}=-0.521-0.692)$.

311

312

Innovation Experiment: Testing Effects of Condition and Social Environment

313

31417 of $22(77 \%)$ subjects approached and solved at least one trial/task. Frequency to peck

315 correlated with frequency to solve (Spearman's correlation: trials with zeros removed: $r(20)=$

$3160.302, \mathrm{p}=0.01)$. Latency to approach and frequency of pecking problem-solving tasks

317 differed across conditions, as subjects waited longer to approach and pecked less frequently

318 in the bark than cup condition (Wilcoxon signed ranks test: latency to approach $-\mathrm{Z}=0.475, \mathrm{p}$

$319=0.028$; frequency of peck $-\mathrm{Z}=-0.458, \mathrm{p}=0.036$ ), with no difference between cup and lid

320 (latency $-\mathrm{Z}=-0.5, \mathrm{p}>0.999$; frequency $-\mathrm{Z}=0.142, \mathrm{p}>0.999$ ), or bark and lid tasks

321 (latency $-Z=0.425 \mathrm{p}=0.06$; frequency $-\mathrm{Z}=-0.317, \mathrm{p}=0.249$ ).

322 Latency to approach and frequency of pecking also differed across social environments.

323 Specifically, subjects waited longer to approach when with conspecifics and non-competing

324 heterospecifics present (2) compared with when alone (1) or when conspecifics and

325 competing heterospecifics were present (3) (Mann-Whitney $\mathrm{U}$ test: 1 vs $2-\mathrm{U}=-33.414, \mathrm{p}=$

$3260.011 ; 2$ vs $3 \mathrm{U}=30.315, \mathrm{p}=0.001 ; 1$ vs $3 \mathrm{U}=-3.099$, $\mathrm{p}>0.999$; Range $=0-1200$ seconds;

327 Mean =718.4; Figure 4A). Subjects also pecked less when conspecifics and non-competing

328 heterospecifics present (2) compared with conspecifics and competing heterospecifics present

329 (3), with no difference compared to being alone (1) (Mann-Whitney $U$ test: 1 vs $2-\mathrm{U}=$

$33020.833, p=0.147 ; 2$ vs $3 \mathrm{U}=-20.357, \mathrm{p}=0.019 ; 1$ vs $3 \mathrm{U}=0.475, \mathrm{p}>0.999$; Range $0-21$

331 pecks; Mean =1.4; Figure 4B). 
332

333

334

335

336

337

338

339

340

341

342

343

344

345

346

347

348

349

350

351

352

353

354

355

356
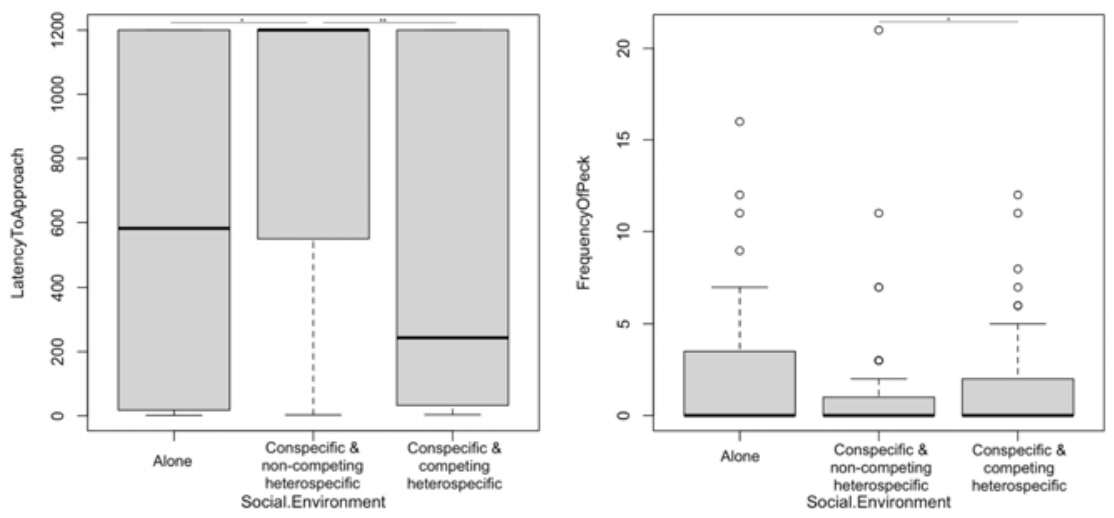

Figure 4. Social environment effect on A) latency to approach (seconds) and B) frequency of peck on problem-solving tasks. Raw data; lines represent median. ${ }^{* *} \mathrm{p}<0.001 ;{ }^{*} \mathrm{p}<0.01$; $* \mathrm{p}<0.05$

\section{Innovation Experiment: Individual Temporal and Contextual Repeatability}

Individuals were temporally repeatable (across 1-3 trials: $\mathrm{ICC}=0.547, \mathrm{p}<0.001, \mathrm{CI}=0.313$ 0.710 ) and contextually repeatable in latency to approach the problem-solving tasks (across bark, cup, lid conditions: $\mathrm{ICC}=0.317, \mathrm{p}=0.040, \mathrm{CI}=-0.048-0.570)$.

\section{Individual-level Performance across Both Experiments}

Using a mean score across round/trial, individual latency to approach three problem-solving tasks correlated with latency to touch familiar food in presence of novel object $(n=20$, ICC $=$ $0.763, \mathrm{p}<0.001, \mathrm{CI}=0.533-0.896)$. Using the mean score, the order of approach within aviary correlated across the three problem solving tasks and the object neophobia condition $(\mathrm{n}=17, \mathrm{ICC}=0.915, \mathrm{p}<0.001, \mathrm{CI}=0.823-0.966$; note. 3 subjects tested alone and 2 subjects - the 2 juveniles - not tested in the bark condition so excluded from analysis).

\section{Discussion}

We tested neophobia (latency to touch familiar food in presence of novel object or novel food) and innovation (latency to approach and frequency of pecking three simple problemsolving tasks) in captive Bali myna. We found effects of condition (neophobia: control, novel 
357

358

359

360

361

362

363

364

365

366

367

368

369

370

371

372

373

374

375

376

377

378

379

380

381

382

383

384

385

386

387

388

389

390

object, novel food; innovation: bark, lid, cup) and social environment (alone, presence of conspecifics and/or heterospecifics that do or do not touch food, i.e., competitors or noncompetitors) on both neophobia and innovation. Individuals were temporally repeatable, though not contextually repeatable in their responses to novelty, while being temporally and contextually repeatable in responses to the problem-solving tasks. Individuals also showed repeatability in their latency responses and order of approaches across both experiments. These findings indicate that, for example, an individual that is quick to touch familiar food beside a novel object is also quick to approach a problem-solving task, and subjects within each aviary are likely to approach the task in a similar order across trials. This study is one of the first to test cognition in Bali myna and provides support for the feasibility of this study species for future research.

Our findings indicating individual repeatability suggest that behavioural responses to novel objects and foods, as well as simple problem-solving foraging-based tasks, may reflect stable traits in this species. Social context has been shown with other species to either facilitate or inhibit behaviours, including neophobia and exploration [18, 29, 30]. For instance, observing group-members eating familiar food facilitates acceptance of novel foods in capuchin monkeys [31]. Bali myna behaviour was influenced by presence of others in both experiments. It appears that the specific identities and/or behaviour of others present played a role, given that conspecific (typically - though not always - a partner) and/or non-competing heterospecifics tended to inhibit Bali myna behaviour, whereas presence of conspecifics (such as the group) and competing heterospecifics (routinely interacted/ate at Bali myna food sites/stimuli) tended to facilitate Bali myna responses. This finding may reflect a 'sociallyinduced' neophobia, where individuals wait for others to take the risk of approaching first, or alternatively related to rank, where they have to wait for access (Mainwaring et al., 2011). The latter finding may be likely with the Bali myna, given they show a consistent order of approach within aviaries which may relate to rank. The importance of the relationship and/or identity of conspecifics has also been shown to influence exploration and/or neophobia in corvids, wolves and dogs $[18,22,30]$. The tested group of young Bali myna in particular presents a rare opportunity (given that this species is most often held in pairs) for future social-based experiments, such as facilitation and tolerance around food sources [32].

The problem-solving tasks selected were similar to one another and simple - lifting or pecking at an object to obtain a visible reward underneath. Despite this, we found differences in responses across conditions. The longer latencies for the bark over the lid and cup conditions is likely due to this being the first task that was tested (i.e., test round 1). 
391 Alternatively, it may be related to the reward (worm) being less visible under the bark than

392 inside the transparent cup or lid. Future work may explore understanding of object

393 permanence to test whether reward visibility influences behavioural responses in problem-

394 solving tasks. We selected the frequency of peck, rather than rate of solving, measure as

395 pecking and solving correlated with one another, and pecking showed higher variability.

396 The main study limitations were uncontrollable aspects of the testing environments -

397 namely variable presence of conspecifics and heterospecifics, which we included as a factor

398 in the analysis. Some heterospecifics had little recordable impact on Bali myna interactions

399 with food or experimental stimuli (e.g., ground-dwelling species like pheasants) thus were

400 referred to as "non-competitors", while others (e.g., spotted laughing-thrush) routinely

401 interacted with these items thus were "competitors". Interestingly, despite appearing to be

402 quite neophobic (i.e., stronger reaction to novel items than control, particularly to novel

403 objects), the Bali myna anecdotally frequently appeared to be one of the more dominant

404 species in mixed-species aviaries as they displaced others (e.g., azure-winged magpies) from

405 test/food sites. We were restricted in timing of data collection due to funding availability

406 therefore testing overlapped with breeding season, which may impact on cognitive

407 performance, motivation and participation. Indeed, one pair did successfully reproduce

408 during testing, which provided a unique opportunity to test two Bali myna juveniles shortly

409 after fledging in the presence of the parents, as well as while alone.

410 These were captive zoo-housed individuals limiting generalisation across the species.

411 Future work should aim to include A) larger captive sample size generally and B) wild/

412 reintroduced birds. Neophobia and innovation could be tested further using different tasks,

413 such as novel predators, variety of novel foods, and more complex problems-solving tasks.

414 Similarly, as neophobia has been found to be context-specific in other species (e.g., corvids

$415[33,34])$, it would be useful to explore the flexibility and manipulations of this behavioural

416 response to novelty. For instance, increasing (e.g., via pairing with aversive stimuli)

417 neophobic reactions to dangerous items, like traps, or decreasing (e.g., via habituation)

418 neophobic responses to novel safe foods prior to release. Other cognitive aspects that are

419 relevant to adaptability, such as social learning i.e., learning from others, would also be

420 useful to test for applying to conservation actions. For example, social facilitation during

421 foraging (capuchin monkeys [35]; carrion crows [32]; bats [36]) and exploring the link

422 between different cognitive abilities, like innovation and social learning [24, 25]. Our present

423 finding that Bali myna are influenced by social context indicates that this would be a useful

424 avenue for future work. 


\section{Conclusion}

427

428 We tested two conservation-relevant cognitive abilities in a little-studied, critically

429 endangered bird species, which could be further implemented across other species, for

430 instance through the ManyBirds framework [27] and utilised in applied sciences.

431 Additionally, behavioural research contributes to conservation by encouraging positive public

432 perception [6], which is particularly important for preventing poaching for the pet trade - a

433 major threat to Bali myna and other species. These findings are promising for the potential of

434 future research with Bali myna and similarly threatened species, particularly those that may

435 be available for both captive and fieldwork, with active conservation programmes including

436 reintroductions.

\section{Acknowledgements}

439 Thank you very much to our participating UK zoological collections: Waddesdon Manor

440 (National Trust/ Rothschild Foundation), Cotswolds Wildlife Park and Gardens, and

441 Birdworld. Special thanks to: Ian Edmans, Gavin Harrison, Llyr Davies (Waddesdon Manor),

442 to Helen Hitchman, Chris Green, Richard Wardle, Natalie Horner (Cotswolds Wildlife Park

443 and Gardens), and to Duncan Bolton, Kat Nicola, Polly Bramham, Natalie Marshall, Rebecca

444 Ive and Ellie Wiczling (Birdworld) for facilitating this research. Thank you to Megan

445 Lambert for helpful feedback on a manuscript draft.

\section{Funding}

448 This research was supported by a Career Support Fund from the University of Cambridge

449 awarded to R.M. The funders had no role in study design, data collection and analysis,

450 decision to publish, or preparation of the manuscript.

Main-text Figure/Table Legends

Figure 1. Novel objects

456 Figure 2. Problem-solving tasks 1 and 2. 1) cup can be lifted to access worm e.g., by pulling 457 string or pushing cup over; 2) lid can be removed e.g., by pushing lid or lifting tab. Problem458 solving task 3 was a piece of wood bark that could be pushed or lifted to access worm. 
460 Figure 3. Latency to touch familiar food (seconds) differed by A) condition and B) social

461 environment. Raw data; lines represent median. *** $\mathrm{p}<0.001 ; * * \mathrm{p}<0.01$

462

463 Figure 4. Social environment effect on A) latency to approach (seconds) and B) frequency of 464 peck on problem-solving tasks. Raw data; lines represent median. *** $\mathrm{p}<0.001 ; * * \mathrm{p}<0.01$; $465 * \mathrm{p}<0.05$

466

467 Table 1. Subject information

468

References

470

4711 Shettleworth, S. J. 2010 Cognition, evolution, and behavior. New York, NY, US: Oxford 472 University Press.

4732 Lee, V. E., Thornton, A. 2021 Animal cognition in an urbanised world. Frontiers in

474 Ecology and Evolution. 9, 120.

4753 Marzluff, J. M., Swift, K. N. 2017 Connecting animal and human cognition to conservation.

476 Current opinion in behavioral sciences. 16, 87-92.

4774 Dingemanse, N. J., Kazem, A. J., Réale, D., Wright, J. 2010 Behavioural reaction norms:

478 animal personality meets individual plasticity. Trends in Ecology \& Evolution. 25, 81-89.

479 (10.1016/j.tree.2009.07.013)

4805 Ashton, B. J., Ridley, A. R., Edwards, E. K., Thornton, A. 2018 Cognitive performance is

481 linked to group size and affects fitness in Australian magpies. Nature. 554, 364-367.

$482(10.1038 /$ nature25503)

4836 Greggor, A. L., Clayton, N. S., Phalan, B., Thornton, A. 2014 Comparative cognition for 484 conservationists. Trends in Ecology \& Evolution. 29, 489-495.

4857 Gosling, L. M., \& Sutherland, W. J. 2000 Behaviour and conservation. . 2001/05/17 ed.

486 Cambridge: Cambridge University Press.

4878 Brakes, P., Dall, S. R. X., Aplin, L. M., Bearhop, S., Carroll, E. L., Ciucci, P., Fishlock, V., 488 Ford, J. K. B., Garland, E. C., Keith, S. A., et al. 2019 Animal cultures matter for 489 conservation. Science. 363, 1032-1034. (10.1126/science.aaw3557)

4909 Griffin, A. S., Blumstein, D. T., Evans, C. S. 2000 Training captive $\square$ bred or translocated 491 animals to avoid predators. Conservation biology. 14, 1317-1326. 
49210 Maloney, R. F., McLean, I. G. 1995 Historical and experimental learned predator

493 recognition in free-living New-Zealand robins. Animal Behaviour. 50, 1193-1201.

49411 Benson-Amram, S., Holekamp, K. E. 2012 Innovative problem solving by wild spotted

495 hyenas. Proceedings of the Royal Society B: Biological Sciences. 279, 4087-4095.

49612 Reader, S. M., \& Laland, K. N. 2003 Animal Innovation. Oxford: Oxford University

497 Press.

49813 Griffin, A. S., Lermite, F., Perea, M., Guez, D. 2013 To innovate or not: contrasting

499 effects of social groupings on safe and risky foraging in Indian mynahs. Animal Behaviour.

500 86, 1291-1300.

50114 Greenberg, R., Mettke-Hofmann, C. 2001 Ecological aspects of neophobia and neophilia

502 in birds. In Current ornithology. (ed.^eds. pp. 119-178: Springer.

50315 Bremner-Harrison, S., Prodohl, P. A., Elwood, R. W. 2004 Behavioural trait assessment as

504 a release criterion: boldness predicts early death in a reintroduction programme of captive-

505 bred swift fox (Vulpes velox). Animal Conservation. 7, 313-320.

$506 \quad(10.1017 / \mathrm{S} 1367943004001490)$

50716 Sol, D., Griffin, A. S., Bartomeus, I., Boyce, H. 2011 Exploring or avoiding novel food

508 resources? The novelty conflict in an invasive bird. PLOS One. 6, e19535.

50917 Cauchoix, M., Chow, P., Van Horik, J., Atance, C., Barbeau, E., Barragan-Jason, G., Bize,

510 P., Boussard, A., Buechel, S. D., Cabirol, A. 2018 The repeatability of cognitive

511 performance: a meta-analysis. Philosophical Transactions of the Royal Society B: Biological

512 Sciences. 373, 20170281.

51318 Miller, R., Bugnyar, T., Pölzl, K., Schwab, C. 2015 Differences in exploration behaviour

514 in common ravens and carrion crows during development and across social context.

515 Behavioral Ecology and Sociobiology. 69, 1209-1220.

51619 Seferta, A., Guay, P. J., Marzinotto, E., Lefebvre, L. 2001 Learning differences between

517 feral pigeons and zenaida doves: the role of neophobia and human proximity. Ethology. 107,

$518 \quad 281-293$.

51920 Jepson, P. R. 2016 Saving a species threatened by trade: a network study of Bali starling

520 Leucopsar rothschildi conservation. Oryx. 50, 480-488. (10.1017/S0030605314001148)

52121 Miller, R., Lambert, M. L., Frohnwieser, A., Brecht, K. F., Bugnyar, T., Crampton, I.,

522 Garcia-Pelegrin, E., Gould, K., Greggor, A. L., Izawa, E.-I., et al. 2021 Individual

523 repeatability, species differences, and the influence of socio-ecological factors on neophobia

524 in 10 corvid species. bioRxiv. 2021.2007.2027.453788. (10.1101/2021.07.27.453788) 
52522 Stöwe, M., Kotrschal, K. 2007 Behavioural phenotypes may determine whether social

526 context facilitates or delays novel object exploration in ravens (Corvus corax). Journal of

527 Ornithology. 148, 179-184.

52823 Greggor, A. L., Masuda, B. M., Flanagan, A. M., Swaisgood, R. R. 2020 Age-related

529 patterns of neophobia in an endangered island crow: implications for conservation and natural

530 history. Animal Behaviour. 160, 61-68. (doi.org/10.1016/j.anbehav.2019.12.002)

53124 Bouchard, J., Goodyer, W., Lefebvre, L. 2007 Social learning and innovation are

532 positively correlated in pigeons (Columba livia). Animal cognition. 10, 259-266.

53325 Miller, R., Schwab, C., Bugnyar, T. 2016 Explorative innovators and flexible use of social

534 information in common ravens (Corvus corax) and carrion crows (Corvus corone). Journal of

535 Comparative Psychology. 130, 328.

53626 Reader, S. 2003 Innovation and social learning: individual variation and brain evolution.

537 Animal biology. 53, 147-158.

53827 Lambert, M., Farrar, B. G., Garcia-Pelegrin, E., Reber, S. A., \& Miller, R. . 2021

539 ManyBirds: A multi-site collaborative Open Science approach to avian cognition and

540 behaviour research. Psyarxiv. (doi:10.31234/osf.io/83xkt)

54128 Péter, A. 2019 Solomon Coder (version beta 19.08.02): a simple solution for behavior

542 coding. Computer programm available at http://solomoncoder.com.

54329 Coleman, S. L., Mellgren, R. L. Neophobia when feeding alone or in flocks in zebra

544 finches, Taeniopygia guttata. Elsevier Science 1994:903-907.

54530 Moretti, L., Hentrup, M., Kotrschal, K., Range, F. 2015 The influence of relationships on

546 neophobia and exploration in wolves and dogs. Animal Behaviour. 107, 159-173.

54731 Visalberghi, E., Addessi, E. 2000 Seeing group members eating a familiar food enhances

548 the acceptance of novel foods in capuchin monkeys. Animal behaviour. 60, 69-76.

54932 Miller, R., Schiestl, M., Whiten, A., Schwab, C., Bugnyar, T. 2014 Tolerance and Social

550 Facilitation in the Foraging Behaviour of Free-Ranging Crows (Corvus corone corone; C. c.

551 cornix). Ethology. 120, 1248-1255. (10.1111/eth.12298)

55233 Greggor, A. L., Jolles, J. W., Thornton, A., Clayton, N. S. 2016 Seasonal changes in

553 neophobia and its consistency in rooks: the effect of novelty type and dominance position.

554 Animal behaviour. 121, 11-20.

55534 Greggor, A. L., Clayton, N. S., Fulford, A. J., Thornton, A. 2016 Street smart: faster

556 approach towards litter in urban areas by highly neophobic corvids and less fearful birds.

557 Animal Behaviour. 117, 123-133. 
55835 Dindo, M., Whiten, A., de Waal, F. B. 2009 Social facilitation of exploratory foraging

559 behavior in capuchin monkeys (Cebus apella). American Journal of Primatology: Official

560 Journal of the American Society of Primatologists. 71, 419-426.

56136 Wright, G. S., Wilkinson, G. S., Moss, C. F. 2020 Social facilitation in short-tailed fruit

562 bats, Carollia perspicillata (Linnaeus). Behaviour. 157, 1193-1210.

563

564 Ethics Statement

565 For animal research, all applicable international, national and/or institutional guidelines for

566 the care and use of animals were followed. This non-invasive behavioural study with birds

567 was conducted adhering to UK laws and regulations and was covered under a non-regulated

568 procedure through University of Cambridge, approved by the Home Office appointed Named

569 Animal Care and Welfare Officer, Named Veterinary Surgeon and Chairperson for the

570 Psychology and Zoology Department Animal User's Management Committee.

571

572 Data Accessibility

573 The full dataset and R script are available at Figshare: DOI 10.6084/m9.figshare.16974298.

\section{Declaration of Interests}

576 The authors declare no competing interests.

577

578 Author Contributions

579 R.M. conceived the study idea, research design, project managed the study, analysed the data, 580 produced the figures, and was awarded funding to support the study. E.G.P. contributed to the 581 research design. R.M. and E.G.P. collected the data. E.G.P. and E.D. coded the videos. R.M. 582 wrote the manuscript, with E.G.P. and E.D. providing feedback on the manuscript. 